\title{
ASSESSMENT OF GENE-XPERT MTB RIF PROGRAM IMPLEMENTATION AND THE CHALLENGES FOR ENHANCED TUBERCULOSIS DIAGNOSIS IN NIGERIA
}

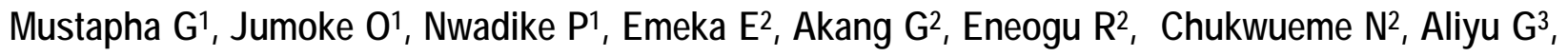 \\ Bhatta GK ${ }^{4}$ \\ ${ }^{1}$ KNCV Tuberculosis Foundation /TB CARE I Project, Plot 564/565 Independence Avenue Abuja Nigeria \\ 2 National Tuberculosis and Leprosy Control Program, Federal Ministry of Health, Abuja, Nigeria \\ ${ }^{3}$ Department of Health and Human Services, Federal Capital Territory, Plot 2 Kapital Street, Garki-Abuja, Nigeria \\ ${ }^{4}$ SAARC TB and HIVIAIDS Center, GPO Box - 9517, Kathmandu, Nepal
}

\begin{abstract}
Introduction: Gene-Xpert MTBRIF, rapid tuberculosis and rifampicin resistance diagnostic technology is implemented in Nigeria to enhance public health response to tuberculosis diagnosis in HIV patients with presumed tuberculosis (TB), and presumed cases of drug resistant TB. The aim of the paper is to share experience on programmatic issues on Xpert MTB RIF roll-out.

Methodology: Program implementation data from 22 Xpert laboratories for period between September 2011 and December 2013 were analyzed to evaluate outcomes and identify challenges and opportunities for strengthening tuberculosis detection in Nigeria.

Results: A total of 12249 patients received single gene-Xpert test at 10 secondary (S), 10 Tertiary (T) and 2 private (P) health facilities over 25 months. The tests were valid in 10948 patients, and 3669/10948 (33.5\%) were positive for Mycobacterium tuberculosis (MTB). In 815/3669 (22.2\%) of the MTB cases, the bacteria were resistant to rifampicin. Rifampicin resistance was inconclusive (indeterminate) in 509/12249 (4.2\%) while the test failed in $792 / 12249$ (6.5\%). The program was noticeably limited to health facilities above primary centers; there were prolonged delays in the diagnosis and treatment with limited on-site synergy between TB/HIV services. Reducing diagnostic delays and integrating TB/HIV services into the gene-Xpert program will enhance early case detection and enrollment for care in Nigeria.

Conclusion: The model Gene-Xpert MTBRIF program implemented in Nigeria targets specific risk groups with high number of cases detected. Diagnoses of tuberculosis and resistance to rifampicin could be enhanced by offering integrated TB/HIV services; improving patient and sample flow/referral; proper documentation of test outcomes and alignment with DR-TB management
\end{abstract}

Key words: Gene-Xpert, Implementation, Challenges, Nigeria

\section{INTRODUCTION}

Few studies have reported the different ways Gene-

\section{Correspondence:}

Dr. Gidado Mustapha

KNCV Tuberculosis Foundation /TB CARE I Project,

Plot 564/565 Independence Avenue Abuja,

Federal Capital Territory, Abuja, Nigeria

E-mail: mustapha.gidado@kncvtbc.org, gidadomansu@yahoo.com.au
Xpert MTBRIF; rapid tuberculosis and rifampicin resistance diagnostic technology is implemented in different settings. ${ }^{1}$ In Nigeria, the program targets specific groups at risk of tuberculosis and cases of tuberculosis at risk of resistance to one of the most powerful drugs currently in use for treating the disease. In 2010, the World Health Organization (WHO) endorsed GeneXpert@ MTB/RIF (Xpert) (Cepheid Inc. New Jersey, USA) for Mycobacterium tuberculosis (MTB) detection in settings with high burden of tuberculosis (TB), and HIV. Since then, access to Xpert 
services has risen in resource limited settings. ${ }^{1-3}$ Available data show that the test is effective and reliable for the rapid diagnosis of pulmonary tuberculosis especially in HIV positive suspects, and multi-drug resistant tuberculosis (MDR TB) in TB cases. ${ }^{2,4,5}$ The massive deployment of Xpert to some resource limited high burden settings is however matched with few reports so far on the program outcomes and challenges.

Xpert is a point-of-care diagnostic test that provides a platform for the integration and scale-up of TB-HIV services in settings where diagnostic delays reduce access to clinical care services. $6,7,8$ Such delays are associated with increased morbidity and mortality among HIV positive clients, and among TB cases infected with multi-drug resistant mycobacteria.9,10 Rifampicin resistance is a precursor to the development of MDR TB, and a reliable predictor of MDR in settings where the prevalence of rifampicin resistant mycobacterium tuberculosis is high. ${ }^{11,12,13}$

Whether Xpert is used as a primary screening tool or as an add-on test for cases with negative smear microscopy outcomes, the uptakes of TB-HIV and MDR-TB services at facility level depends on a number of factors such as effective HIV counseling and testing services (HCT), coordination between TB and HIV programs, timely sample transfer and retrieval of results and effective documentation. Successful implementation of the Xpert program in resource limited settings may be hampered by high cost of the test, poor maintenance, underutilization and hard operational conditions (high temperatures, irregular power supplies and low capacity human resources). ${ }^{14,15}$ Nationwide implementation of Xpert program requires high level of advocacy, adequate preparation, sites selection and indepth trainings.

Xpert program in Nigeria is largely implemented by the KNCV Tuberculosis Foundation in partnership with the government of Nigeria, with support from the U.S agency for international development (USAID). The implementation program is supervised by the national TB control program (NTP) through an advisory committee of experts: the country GeneXpert advisory committee (C-GAT). The C-GAT is responsible for the coordination of Xpert implementation activities by all implementing partners. The C-GAT is assisted by technical staff from the KNCV foundation and Cepheid Inc., in the planning, facility assessment and selection; development of strategies for the program roll-out; establishment of diagnostic algorithms, standard operating procedures and reporting formats according to the WHO recommendations.

In this article we evaluate the model Xpert program implemented in Nigeria with reference to the program's data generated to assess outcomes and challenges faced in the roll-out and scale-up of the program in Nigeria.

\section{METHODOLOGY}

A retrospective Xpert program data from the 22 sites (10 secondary, 10 tertiary, and 2 private health facilities) supported by KNCV/TB CARE I project in Nigeria between September 2011 and December 2013 were reviewed. One Xpert machine per site (facility) was installed in the sites from September, 2011 to September, 2013. Patients were offered Xpert tests at these sites if they had HIV with presumptive tuberculosis or if they had poor response to category I and, or II tuberculosis treatment regimen; relapsed after tuberculosis treatment; returned after treatment interruption; or had contact with a known case of MDRTB. As part of the standard of care, documentation of patients' HIV status was required. All program report forms, monitoring and evaluation report sheets, site planning, preparations and take-off reports from the date a site was activated until December, 2013 were reviewed. The quarterly C-GAT meetings and evaluation reports were also reviewed.

De-identified quantitative data on the number of patients enrolled at different sites including their Xpert and HIV test outcomes were abstracted. Xpert tests were valid if MTB and rifampicin resistance (RIFr) presence or absence were determined. Indeterminate if only MTB presence or absence was determined, and failed if the presence or absence of MTB cannot be determined (invalid) or test error or no result signals were shown. HIV status was classified as positive, negative or unknown (if undocumented). The various sites were coded as follows: S1 through S10, for the 10 secondary sites; $\mathrm{T} 1$ through $\mathrm{T} 10$ for the 10 tertiary sites and $\mathrm{P} 1, \mathrm{P} 2$ for the 2 private sites.

The abstracted data were organized into cell counts in which descriptive values were provided along with frequencies and proportions. In computing proportions, failed and, or indeterminate results were carefully excluded or included from the denominators depending on what was reported. In comparing the test outcomes, we pooled data from the same type sites into three 
groups: S, T and P; representing data from the 10 secondary, 10 tertiary and 2 private sites respectively. We then constructed 2-way table: variables of interest by group type (3 types), and performed a Chi-square test; if it was significant we followed with pair wise 2 by 2 table and a Chi-square test. Data consistencies with the hypotheses of no difference were assessed by the $p$-values (level of significance $=0.05$ ) reported while the strength of associations was given by the odds ratios and $95 \%$ confidence intervals of the odds ratios estimated. Qualitative data reporting challenges with program implantation were tabulated with frequencies and pattern of reported challenges summarized to which workable solutions or recommendations provided.

\section{RESULTS}

\section{GeneXpert Test outcomes}

From September, 2011 to December, 2013, 12249 presumptive cases of drug resistant (DR) TB and presumed TB in HIV infected patients were offered single Xpert tests at 22 sites. The number of tests and yields of MTB and RIFr at the 22 different sites were summarized in table 1. Of those, $7567(61.8 \%), 3419$ $(27.9 \%)$ and $1263(10.3 \%)$ were enrolled at secondary, tertiary and private level health facilities (sites) respectively. The tests were valid in 10948 patients, and of those, 3669 (33.5\%) had Mycobacterium tuberculosis (MTB) infection with rifampicin resistance (RIFr) in 815/3669 (22\%). Among the resistant cases, $119(14.6 \%)$ had co-infection with HIV, 444 (55.5\%) were negative of the HIV while in $252(30.9 \%)$ cases the HIV status was not documented (see table 2).

Table 1. The prevalence of tuberculosis (TB) and resistance to rifampicin (RIFr) among Xpert testing clients by site

\begin{tabular}{|l|l|l|l|l|}
\hline \multicolumn{1}{|c|}{ Site } & \multicolumn{1}{c|}{ Site } & Valid Xpert & \multicolumn{2}{c|}{ MTB Cases } \\
\hline & SAT $_{\text {AT }}$ & Nc & $n$ & $\%$ \\
\hline Total & & $\mathbf{1 0 9 4 8}$ & $\mathbf{3 6 6 9}$ & $\mathbf{3 3 . 5}$ \\
\hline S1 & 10.2011 & 1156 & 352 & 30.5 \\
\hline S2 & 10.2011 & 534 & 215 & 40.3 \\
\hline S3 & 4.2012 & 1121 & 547 & 48.8 \\
\hline S4 & 4.2012 & 784 & 259 & 33.0 \\
\hline S5 & 10.2011 & 509 & 249 & 48.9 \\
\hline S6 & 10.2011 & 1388 & 413 & 29.8 \\
\hline S7 & 10.2011 & 588 & 200 & 34.0 \\
\hline S8 & 10.2012 & 537 & 162 & 30.2 \\
\hline S9 & 10.2013 & 73 & 34 & 46.6 \\
\hline S10 & 10.2013 & 56 & 23 & 41.1 \\
\hline
\end{tabular}

SAARC J TUBER LUNG DIS HIV/AIDS, 2015 XII(2)

\begin{tabular}{|l|l|l|l|l|}
\hline T1 & 10.2012 & 206 & 67 & 32.5 \\
\hline T2 & 10.2012 & 232 & 75 & 32.3 \\
\hline T3 & 10.2012 & 219 & 93 & 42.5 \\
\hline T4 & 10.2011 & 1057 & 292 & 27.6 \\
\hline T5 & 10.2012 & 201 & 40 & 19.9 \\
\hline T6 & 10.2012 & 849 & 251 & 29.6 \\
\hline T7 & 7.2013 & 155 & 49 & 31.6 \\
\hline T8 & 7.2013 & 123 & 28 & 22.8 \\
\hline T9 & 10.2013 & 33 & 15 & 45.5 \\
\hline T10 & 10.2013 & 25 & 8 & 32.0 \\
\hline P1 & 10.2011 & 1087 & 293 & 27.0 \\
\hline P2 & 10.2013 & 15 & 4 & 26.7 \\
\hline
\end{tabular}

$\mathrm{S}_{\mathrm{AT}}=$ Month and year the site was activated

$\mathrm{N}_{\mathrm{c}}=$ Total number with valid Xpert test

$\mathrm{S}=$ Secondary; $\mathrm{T}=$ Tertiary; $\mathrm{P}=$ Private

Table 2. The prevalence of tuberculosis (TB) and resistance to rifampicin (RIFr) by HIV status among Xpert testing clients by site

\begin{tabular}{|l|l|l|l|l|l|l|l|l|}
\hline Site & \multicolumn{2}{l|}{ RIFr } & \multicolumn{2}{l|}{ RIFr HIV+ } & \multicolumn{2}{l|}{ RIFr HIV- } & \multicolumn{2}{l|}{ RIFr HIV \pm} \\
\hline & $n$ & $\%$ & $n$ & $\%$ & $n$ & $\%$ & $n$ & $\%$ \\
\hline Total & $\mathbf{8 1 5}$ & $\mathbf{2 2 . 2}$ & $\mathbf{1 1 9}$ & $\mathbf{1 4 . 6}$ & $\mathbf{4 4 4}$ & $\mathbf{5 5 . 5}$ & $\mathbf{2 5 2}$ & $\mathbf{3 0 . 9}$ \\
\hline S1 & 64 & 18.2 & 11 & 17.2 & 29 & 45.3 & 24 & 37.5 \\
\hline S2 & 69 & 32.1 & 9 & 13.0 & 60 & 86.7 & 0 & 0.0 \\
\hline S3 & 106 & 19.4 & 15 & 14.2 & 60 & 56.6 & 31 & 29.2 \\
\hline S4 & 43 & 16.6 & 5 & 11.6 & 10 & 23.3 & 28 & 65.1 \\
\hline S5 & 80 & 32.1 & 3 & 3.8 & 55 & 68.8 & 22 & 27.5 \\
\hline S6 & 102 & 24.7 & 8 & 7.8 & 45 & 44.1 & 49 & 48.0 \\
\hline S7 & 32 & 16.0 & 7 & 21.9 & 19 & 59.4 & 6 & 18.8 \\
\hline S8 & 24 & 14.8 & 6 & 25.0 & 9 & 37.5 & 9 & 37.5 \\
\hline S9 & 7 & 20.6 & 0 & 0.0 & 2 & 28.6 & 5 & 71.4 \\
\hline S10 & 2 & 08.7 & 1 & 50.0 & 1 & 50.0 & 0 & 0.0 \\
\hline T1 & 14 & 20.9 & 1 & 7.1 & 5 & 35.7 & 8 & 57.1 \\
\hline T2 & 13 & 17.3 & 0 & 0.0 & 10 & 76.9 & 3 & 23.1 \\
\hline T3 & 13 & 14.0 & 4 & 30.8 & 2 & 15.4 & 7 & 53.8 \\
\hline T4 & 109 & 37.3 & 16 & 14.7 & 61 & 56.0 & 32 & 29.4 \\
\hline T5 & 8 & 20.0 & 1 & 12.5 & 06 & 75.0 & 1 & 12.5 \\
\hline T6 & 56 & 22.3 & 11 & 19.6 & 28 & 50.0 & 17 & 30.4 \\
\hline T7 & 6 & 12.2 & 1 & 16.7 & 5 & 83.3 & 0 & 0.0 \\
\hline T8 & 9 & 32.1 & 2 & 22.2 & 7 & 77.8 & 0 & 0.0 \\
\hline T9 & 6 & 40.0 & 0 & 0.0 & 6 & 100.0 & 0 & 0.0 \\
\hline T10 & 1 & 12.5 & 0 & 0.0 & 1 & 100.0 & 0 & 0.0 \\
\hline P1 & 50 & 17.1 & 17 & 34.0 & 23 & 46.0 & 10 & 20.0 \\
\hline P2 & 1 & 25.0 & 1 & 100. & 0 & 0.0 & 0 & 0.0 \\
\hline
\end{tabular}

RIF HIV+ = HIV positive TB cases resistant to rifampicin RIF HIV- = HIV negative TB cases resistant to rifampicin RIF HIV $\pm=$ HIV unknown TB cases resistant to rifampicin $S=$ Secondary; $T=$ Tertiary; $P=$ Private

The Xpert tests were indeterminate in 509/12249 $(4.2 \%)$, and failed in $792 / 12249(6.5 \%)$. Of all patients tested the proportion of MTB cases with undocumented HIV status was 1058/12249 (8.6\%). However, within the MTB cases, the proportion of cases with undocumented HIV status was 1058/3669 (28.8\%). The distribution of the indeterminate test findings, failed Xpert tests, and 
MTB cases with undocumented HIV status by site-type among all patients tested is summarized in figure 1.

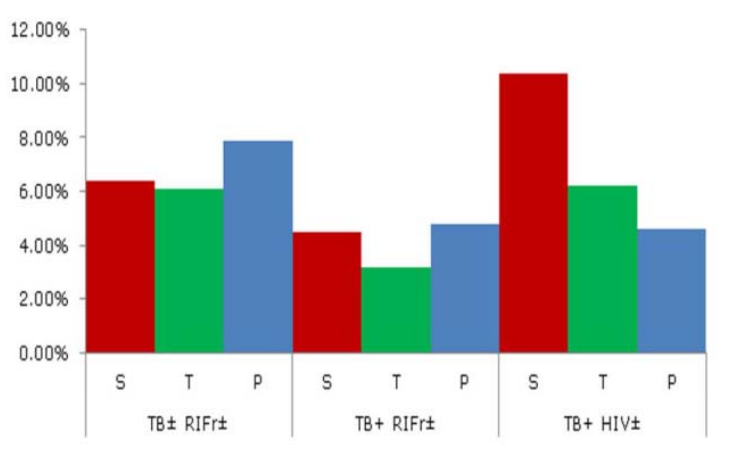

Figure 1. Distribution of Failed ( $T B \pm R I F r \pm)$, Indeterminate (TB+ RIFr \pm ) Xpert test results and MTB cases with undocumented HIV status (TB+ HIV \pm ) across the secondary $(\mathrm{S})$, tertiary $(\mathrm{T})$ and private $(\mathrm{P})$ site

Comparisons of the site-type with respect to indeterminate, failed result and undocumented' HIV status showed the three sites to differ significantly. While the tertiary site was less likely to yield test results that were indeterminate compared to the secondary and private sites $(\mathrm{OR}=0.72,95 \% \mathrm{Cl}: 0.58,0.90$; $\mathrm{p}=0.03 ; \quad \mathrm{OR}=0.66, \quad 0.48, \quad 0.91 ; \mathrm{p}=0.01)$, the nondocumentation of HIV status was more likely among patients who visited secondary site than tertiary, and private $(\mathrm{OR}=1.75,95 \%$ confidence interval $(\mathrm{Cl}): 1.49$ $2.04, \quad p=<.0001 ; \quad \mathrm{OR}=2.44, \quad 95 \% \mathrm{Cl}: 1.85-3.20 ; \quad p=$ $<.0001$ ) (table 3).

\section{Challenges in the roll-out of Xpert services}

A review of the reports on program monitoring and evaluation showed that the program was implemented in selected secondary, tertiary and private levels health facilities .None of the primary health care facilities assessed by the program implementers met the criteria selection, mainly based on the suitability for Xpert machine installation. Logistical issues, such as, lack of alternative power supply, limited laboratory space and inadequate human resources were listed as the reasons for the failures of the primary health facilities. However, even among the secondary and tertiary facilities selected for the program, alternative sources of power supply were lacking in some. There were frequent reports of power inverter failures from more than half of the selected sites, in addition to insufficient human resources and poorly equipped laboratories (without work bench, air-condition, refrigerator etc.).

Machines utilizations were generally suboptimal because the program selectively targets presumptive cases of drug resistant TB and HIV cases with presumptive TB. There were delays in getting cases of MDR-TB enrolled into drug treatment despite increase in MDR-TB treatment centers from a single facility (24 beds capacity in 2010) to ten hospitals with over 285 beds capacity nationwide according to the 2013 Ministry of Health's annual report on tuberculosis and leprosy captured in one of the program's reports. Codes were not provided for some of the error results and indeterminate outcomes were often labelled invalid in some sites.

Documentation of HIV status was also inconsistent and no reasons were given for client whose HIV status was

\begin{tabular}{|c|c|c|c|c|c|c|c|c|}
\hline Outcome & Site Type & Yes, Yes & Yes, No & No, Yes & No, No & OR & $95 \% \mathrm{Cl}$ & P-value \\
\hline \multirow[t]{3}{*}{ Indetr } & T vs. S & 111 & 337 & 3308 & 7230 & 0.72 & $0.58,0.90$ & 0.030 \\
\hline & S vs. P & 337 & 61 & 7230 & 1202 & 0.99 & $0.69,1.21$ & 0.548 \\
\hline & T vs. $P$ & 111 & 61 & 3308 & 1202 & 0.66 & $0.48,0.91$ & 0.010 \\
\hline \multirow[t]{3}{*}{ Failed } & S vs. T & 484 & 208 & 7083 & 3211 & 1.05 & $0.89,1.25$ & 0.532 \\
\hline & S vs. $P$ & 484 & 100 & 7083 & 1163 & 0.79 & $0.64,0.99$ & 0.042 \\
\hline & T vs. P & 208 & 100 & 3211 & 1163 & 0.75 & $0.59,0.97$ & 0.021 \\
\hline \multirow[t]{3}{*}{ HIV \pm} & S vs. T & 787 & 213 & 6780 & 3206 & 1.75 & $1.49,2.04$ & $<.001$ \\
\hline & S vs. P & 787 & 58 & 6780 & 1205 & 2.44 & $1.85,3.20$ & $<.001$ \\
\hline & T vs. $P$ & 213 & 58 & 3206 & 1205 & 1.38 & $1.02,1.86$ & 0.030 \\
\hline
\end{tabular}

OR: odds ratio, Cl: confidence interval, HIV \pm : HIV status undocumented 
not documented. Patient HIV status is coded and reflected in the laboratory requests forms that accompany the sputum specimens, in situations where the sputum samples were collected and brought to the center from clinics without Xpert services, or in program sites where patients walk in with the request form to provide sputum samples. The non-reflection of HIV status was more frequent with samples coming from centers other than where the machines were located. for samples brought to the site from collection centers that were remotely located. Logistical delays in getting the data collection tools to the sites were a frequent complaint. Finally, there were concerns of lack of awareness of the existence of Xpert services among clinicians at different service points within and outside where the machines were installed. Some of these challenges and suggested ways to address them were summarized in table 4.

\begin{tabular}{|c|c|c|}
\hline Challenge & Comments & Suggestions \\
\hline $\begin{array}{l}\text { Sample transfer and results retrieval } \\
\text { strategies }\end{array}$ & $\begin{array}{l}\text { No standardized sample transfer } \\
\text { mechanisms between sites with } \\
\text { machines and those without, and } \\
\text { sites that are farther located. }\end{array}$ & $\begin{array}{l}\text { Consider equipping and decentralizing } \\
\text { services to Primary Health Centers in } \\
\text { densely populated areas lacking Xpert } \\
\text { services. }\end{array}$ \\
\hline $\begin{array}{l}\text { Proper documentation and reporting of } \\
\text { test outcomes }\end{array}$ & $\begin{array}{l}\text { Non-adherence to protocol and } \\
\text { occasional delays in the supply of } \\
\text { data collection tools may have } \\
\text { contributed to the inconsistencies } \\
\text { in test results documentation. }\end{array}$ & $\begin{array}{l}\text { Regular supervision and training of site staff } \\
\text { on proper documentation of results, sample } \\
\text { collections, processing, and testing. }\end{array}$ \\
\hline $\begin{array}{l}\text { Non-documentation of patients HIV } \\
\text { status and poor integration of HIV-TB } \\
\text { services at site level. }\end{array}$ & $\begin{array}{l}\text { HIV infection is an eligibility } \\
\text { criterion for access to Xpert } \\
\text { services. Screening TB cases for } \\
\text { HIV and vice-versa is also part of } \\
\text { the standard of care. }\end{array}$ & $\begin{array}{l}\text { Offer HIV counselling and testing services at } \\
\text { the point of Xpert testing to cases with } \\
\text { unknown HIV status. Provide reasons for } \\
\text { unknown status; example, refusal of HIV } \\
\text { test. }\end{array}$ \\
\hline Frequent power interruption & $\begin{array}{l}\text { All the machines at the secondary } \\
\text { sites run on alternative source of } \\
\text { electricity for most of the working } \\
\text { hours in a day }\end{array}$ & $\begin{array}{l}\text { Collaborate with site HIV program. } \\
\text { Generators supporting the CD4 count } \\
\text { machines in some sites could be used to } \\
\text { support Xpert program. Consider solar } \\
\text { energy as an alternative source of power. }\end{array}$ \\
\hline Long programmatic turnaround time & $\begin{array}{l}\text { Takes days and even weeks from } \\
\text { sample collection to diagnosis. }\end{array}$ & $\begin{array}{l}\text { Internet based GxAlert is being introduced } \\
\text { which sends instant results via text } \\
\text { messages to both patients and clinicians. } \\
\text { Improve flow of patients, samples, and } \\
\text { results at facility level. }\end{array}$ \\
\hline $\begin{array}{l}\text { Low awareness of Xpert program and } \\
\text { services among clinicians }\end{array}$ & $\begin{array}{l}\text { Xpert is not part of routine TB and } \\
\text { TB/HIV training program in many } \\
\text { sites. Many clinicians in such sites } \\
\text { were unaware of the existing Xpert } \\
\text { program at their sites }\end{array}$ & $\begin{array}{l}\text { Create awareness through presentations at } \\
\text { clinical meetings and updates trainings. } \\
\text { Integrate of Xpert into all TB \& TB/HIV } \\
\text { training manuals. }\end{array}$ \\
\hline $\begin{array}{l}\text { Inefficient Xpert cartridges supply } \\
\text { management system }\end{array}$ & $\begin{array}{l}\text { While some sites were low or } \\
\text { running out of cartridges others } \\
\text { have expired stock of cartridges }\end{array}$ & $\begin{array}{l}\text { Cartridges supply should match site needs. } \\
\text { GxAlert provides daily utilization of } \\
\text { cartridges by site. }\end{array}$ \\
\hline
\end{tabular}

However, even among patients from the program sites, missing data on HIV status was common.

In many sites, inefficient sample and result retrieval flow system resulted in prolonged time to diagnoses after samples were collected. Programmatic turnaround time from sample collection to diagnoses varied with some running into several weeks due to logistical delays in sample transportation and result retrievals particularly

\section{DISCUSSION}

The phased introduction and scale-up of Xpert program in Nigeria is yielding encouraging outcomes from testing specific population groups. Access to the program is limited to cases at risk of drug resistant tuberculosis (DR-TB) and HIV infected patients with suggestive symptoms of tuberculosis unlike in several other countries where the test is offered to all 
presumptive cases of tuberculosis. 16,17. The high proportion of the MTB cases resistant to rifampicin indicates that risk groups for DR-TB are being well targeted. Rifampicin resistance is used as a proxy for MDR-TB and the predictive value of positive Xpert rifampicin resistance for MDR-TB improves greatly with increasing prevalence of resistance to rifampicin. ${ }^{13}$

The scale-up of DR-TB treatment centers mentioned, to match the demand created by increased detection of the resistant cases, from a single 24 beds capacity facility in 2010 to over 285 beds capacity in 10 facilities in 2013 will improve access to treatment for resistant cases. Care should however, be taken to ensure that this apparent success of improved access to treatment is not diminished by delays in treatment initiation due to poor flow of samples and test results. As the program expands, resistant TB case detection will continue to rise. Addition of treatment sites may not provide the needed solution to the delays in treatment initiation if the logistical problems associated with sample transfer, diagnosis, results retrieval and processing of patients for enrollment are not addressed. Long programmatic turnaround time is a challenge with Xpert implementation in most settings ${ }^{3}$ but diagnostic delays exceeding a few days and getting into several weeks could significantly impact on the quality of care and synergy with other programs. ${ }^{8}$

The failure of any of the primary care facilities inspected to qualify for the program is a concern because the long-term objective is to make these services more accessible at the community level. Meeting the infrastructural and operational needs of the primary sites is an important consideration for the decisionmakers. A recent study indicated that Xpert test can successfully be run by a nurse in primary-care clinics in settings with limited resources. ${ }^{[17]}$ With adequate infrastructure, sufficient capacity and strong supervision, more patients will have access to the services at the community level.

For effective program evaluation and the use of Xpert for intensified TB case findings among patients with HIV co-infection, it is essential that HIV counseling and testing (HCT) services are offered to all patients in Xpert program and their status documented. ${ }^{18-20}$ One in three of all the TB cases identified by Xpert in this program have no documented evidence of access to HCT. This makes it hard to evaluate the uptake and impact of the program among all HIV cases with presumptive TB. The proportion of MTB cases without documented HIV status is higher among patients tested at secondary health facilities, the sites where the majority accessed Xpert services at the moment. This calls for improve co-ordination in such centers between the Xpert program and the HIV services, at the sites and from sputum collection centers to enable tracking of patients HIV status and capturing that information into the Xpert program database. Additionally, HIV test could be offered to patients who walked in to provide sputum specimen and whose HIV status is not reflected on their test request forms.

The focus on specific groups could be programmatically efficient. The high number of cases with drug resistant TB attests to this. However, the more the target groups are narrowed, the less is the number of eligible patients to take the test. The machine and the expensive cartridges are then underutilized. Given the setting, interruption in power supply and excessive temperatures are anticipated. However, with the existing complementary programs such as the US President's Emergency Program for AIDs Relief (PEPFAR) in some of the sites, working out modalities to link Xpert machines to generators supporting other programs where feasible could minimize the effect of frequent power interruption on the test uptakes and outcomes.

Xpert rollout and scale up program in Nigeria is recording considerable successes, however, limiting the services to health facilities above primary centers; prolonged delays in the diagnosis and treatment; lack of on-site synergy between TB/HIV services and in efficient sample and result retrieval flow system are challenges to the program implementation. Equally, the sole objective of obtaining same day result to initiate treatment may be hard to achieve given the delays from poor sample and patient flows which are likely to worsen when the algorithm is altered to target all suspected TB cases. Program decentralization should consider equipping and building capacity in facilities nearest to the people especially the primary health care sites.

\section{CONCLUSION}

Despite the fact that Xpert MTB RIF machines was aimed to be place at the lowest health care delivery level for ease of access, lack of infrastructural support and human resource were key barriers in Nigeria. Diagnoses of tuberculosis and resistance to rifampicin could be enhanced by offering integrated TB/HIV 
services; improving patient and sample flow/referral; proper documentation of test outcomes and alignment with DR-TB management

Acknowledgement: The authors wish to thank the Abuja Office of the US Agency for International Development and the staff of the KNCV/TB CARE I project for the investment and support for Xpert program implementation in Nigeria. Special thanks go to Sanne Van Kampen and Manuela R. for their numerous contributions and technical support.

\section{REFERENCES}

1. Creswell J, Codlin AJ, Andre E, et al. Results from early programmatic implementation of Xpert MTB/RIF testing in nine countries. BMC Infect Dis. 2014;14:2.

2. Van Rie A, Page-Shipp L, Scott L, Sanne I, Stevens W. Xpert((R)) MTB/RIF for point-of-care diagnosis of TB in high-HIV burden, resource-limited countries: hype or hope? Expert Rev Mol Diagn. Oct 2010;10(7):937-46.

3. Boehme CC, Nicol MP, Nabeta $P$, et al. Feasibility, diagnostic accuracy, and effectiveness of decentralised use of the Xpert MTB/RIF test for diagnosis of tuberculosis and multidrug resistance: a multicentre implementation study. Lancet. Apr 30 2011;377(9776):1495-1505.

4. Small PM, Pai M. Tuberculosis diagnosis--time for a game change. N Engl J Med. Sep 9 2010;363(11):107071.

5. Marlowe EM, Novak-Weekley SM, Cumpio J, et al. Evaluation of the Cepheid Xpert MTB/RIF assay for direct detection of Mycobacterium tuberculosis complex in respiratory specimens. J Clin Microbiol. Apr 2011;49(4):1621-23.

6. Boehme CC, Nabeta $P$, Hillemann $D$, et al. Rapid molecular detection of tuberculosis and rifampin resistance. N Engl J Med. Sep 9 2010;363(11):1005-15.

7. Helb D, Jones M, Story E, et al. Rapid detection of Mycobacterium tuberculosis and rifampin resistance by use of on-demand, near-patient technology. J Clin Microbiol. Jan 2010;48(1):229-37.

8. Narasimooloo R, Ross A. Delay in commencing treatment for MDR TB at a specialised TB treatment centre in KwaZulu-Natal. S Afr Med J. Jun 2012;102(6 Pt 2):36062.

9. Whalen C, Horsburgh CR, Hom D, Lahart C, Simberkoff $M$, Ellner J. Accelerated course of human immunodeficiency virus infection after tuberculosis. $A m \mathrm{~J}$ Respir Crit Care Med. Jan 1995;151(1):129-35.
10. Kawai V, Soto G, Gilman RH, et al. Tuberculosis mortality, drug resistance, and infectiousness in patients with and without HIV infection in Peru. Am J Trop Med Hyg. Dec 2006;75(6):1027-33.

11. Lawn SD, Brooks SV, Kranzer K, et al. Screening for HIVassociated tuberculosis and rifampicin resistance before antiretroviral therapy using the Xpert MTB/RIF assay: a prospective study. PLoS Med. Jul 2011;8(7):e1001067.

12. Steingart KR, Sohn H, Schiller I, et al. Xpert(R) MTB/RIF assay for pulmonary tuberculosis and rifampicin resistance in adults. Cochrane Database Syst Rev. 2013;1:CD009593.

13. Trebucq A, Enarson DA, Chiang $C Y$, et al. Xpert $(R)$ MTB/RIF for national tuberculosis programmes in lowincome countries: when, where and how? Int J Tuberc Lung Dis. Dec 2011;15(12):1567-72.

14. Dowdy DW, Cattamanchi A, Steingart KR, Pai M. Is scale-up worth it? Challenges in economic analysis of diagnostic tests for tuberculosis. PLOS Med. Jul 2011;8(7):e1001063.

15. Meyer-Rath G, Schnippel K, Long L, et al. The impact and cost of scaling up GeneXpert MTB/RIF in South Africa. PLoS One. 2012;7(5):e36966.

16. Raizada N, Sachdeva KS, Sreenivas A, et al. Feasibility of decentralised deployment of Xpert MTB/RIF test at lower level of health system in India. PLOS One. 2014;9(2):e89301.

17. Theron G, Zijenah L, Chanda D, et al. Feasibility, accuracy, and clinical effect of point-of-care Xpert MTB/RIF testing for tuberculosis in primary-care settings in Africa: a multicentre, randomised, controlled trial. Lancet. Feb 1 2014;383(9915):424-35.

18. Balcha TT, Sturegard E, Winqvist N, et al. Intensified Tuberculosis Case-Finding in HIV-Positive Adults Managed at Ethiopian Health Centers: Diagnostic Yield of Xpert MTB/RIF Compared with Smear Microscopy and Liquid Culture. PLoS One. Jan 22 2014;9(1):e85478.

19. Abed Al-Darraji HA, Abd Razak H, Ng KP, Altice FL, Kamarulzaman $A$. The diagnostic performance of a single GeneXpert MTB/RIF assay in an intensified tuberculosis case finding survey among HIV-infected prisoners in Malaysia. PLoS One. 2013;8(9):e73717.

20. Alvarez-Uria G, Azcona JM, Midde M, Naik PK, Reddy S, Reddy R. Rapid Diagnosis of Pulmonary and Extrapulmonary Tuberculosis in HIV-Infected Patients. Comparison of LED Fluorescent Microscopy and the GeneXpert MTB/RIF Assay in a District Hospital in India. Tuberc Res Treat. 2012;2012:932862. 